\title{
Ana María Crespo Oviedo (1938-2004)
}

\section{María Rosa Avilez Moreno et Véronique Darras}

\section{OpenEdition}

\section{Journals}

Édition électronique

URL : https://journals.openedition.org/jsa/1740

DOI : 10.4000/jsa. 1740

ISSN : $1957-7842$

\section{Éditeur}

Société des américanistes

\section{Édition imprimée}

Date de publication : 5 juin 2004

Pagination : 175-180

ISSN : 0037-9174

\section{Référence électronique}

María Rosa Avilez Moreno et Véronique Darras, « Ana María Crespo Oviedo (1938-2004) », Journal de

la Société des américanistes [En ligne], 90-2 | 2004, mis en ligne le 17 novembre 2005, consulté le 04 septembre 2022. URL : http://journals.openedition.org/jsa/1740 ; DOl : https://doi.org/10.4000/jsa. 1740 


\title{
ANA MARÍA CRESPO OVIEDO
}

\author{
$(1938-2004)$
}

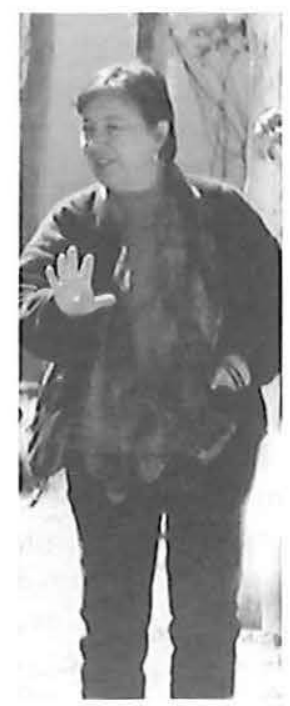

Le 17 octobre dernier, à la suite d'une maladie incurable qui affecta son corps, mais jamais son esprit, Ana María Crespo Oviedo nous a quittés. Jusqu'au dernier moment, elle a continué à travailler avec la même énergie qui l'a toujours caractérisée, à porter un regard attentif aux autres et à suivre dans le détail les événements politiques qui se produisaient chaque jour.

Elle naquit en 1938, dans la ville de Mexico. Dès son plus jeune âge elle montra une attitude combative face à la réalité sociale, qui la conduisit plus tard à s'engager politiquement, engagement qui s'exprima dans tous les aspects de sa vie. En 1962, elle entra à l'ENAH (Escuela nacional de antropología e historia), ce qui constitua le démarrage d'une carrière professionelle intense. Dix ans plus tard, dans son mémoire de maîtrise "Villa de Reyes, San Luis Potosí : un núcleo agrícola en la fiontera norte de Mesoamérica », apparaissait son intérêt pour l'étude des frontières et des dynamiques culturelles du Centre-Nord du Mexique, une région qui, jusqu'alors, était délaissée par l'archéologie en raison de sa supposée nature marginale. En 1972, elle s'intégra dans le projet Tula du Département des monuments préhispaniques et développa, avec d'autres, une étude régionale pionnière tenant compte du double aspect historique et géographique. À partir de ce moment, elle commença à établir des relations de travail et d'amitié 
avec des collègues qui ont, par la suite, partagé avec elle intérêts et projets pour les secteurs du Guanajato et du Querétaro.

Quelques années plus tard, la décentralisation de l'Institut national d'anthropologie et d'histoire (INAH) conduisit à la création des premiers centres régionaux. En 1979 Ana rejoignit le nouveau Centre INAH de Guanajuato-Querétaro. À partir de là, elle multiplia les programmes et les projets ayant pour objectif d'enregistrer et d'assurer la sauvegarde des témoignages archéologiques du Guanajuato, ainsi que d'approfondir la connaissance des peuples préhispaniques du Centre-Nord et de leur diversité culturelle, refusant catégoriquement de les considérer comme marginaux par rapport au développement mésoaméricain. Pour aborder les processus socio-politiques qui caractérisaient ces populations, elle formula un modèle général du développement, d'où elle tirait des hypothèses de travail, une approche qu'elle ne cessa de préciser dans de nombreuses publications. En 1984, elle fut une des fondatrices du centre de l'INAH du Querétaro et recentra alors son intérêt surtout sur le sud de la vallée du Querétaro, où elle dirigea le projet archéologique El Cerrito. Au niveau professionnel, elle suscita - et participa à - la création d'un groupe de chercheurs sur la région, convaincue que la recherche ne peut être conduite que de manière collective. De fait elle ne pouvait concevoir la pratique de son métier sans échanges récurrents d'idées avec ses collègues. Sa curiosité intellectuelle faisait qu'elle était toujours à la recherche d'autres perspectives permettant d'aborder les sociétés qui occupèrent, à différentes périodes, le Centre-Nord. Cet état d'esprit la porta à promouvoir l'interdisciplinarité, en même temps qu'elle-même se lançait dans d'autres domaines. Très tôt, à sa formation d'anthropologue, elle ajouta des études en géographie qu'elle fit à l'Université nationale autonome de Mexico (UNAM) et qui éveillèrent, chez elle, une passion pour l'étude des phénomènes dans leur dimension spatiale et leurs implications territoriales. L'orientation scientifique de ses recherches fut indissociable de son engagement politique, de sorte qu'elle privilégia l'étude du concept de territoire conçu comme manifestation d'un pouvoir. Territoire et pouvoir sont présents et entremêlés tout au long de son œuvre jusqu'à la plus récente, se cristallisant dans une thèse de doctorat quasiment achevée. Dans ce travail, qui concerne la conquête et les formes de colonisation du Gran Chichimeca vues à travers le prisme de la mémoire otomi, se conjuguaient l'ethnohistoire, l'ethnologie et l'archéologie, bousculant la partition en disciplines isolées pour aborder de manière globale son objet d'étude. La cohérence d'Ana María Crespo Oviedo la conduisit également à s'engager activement dans la vie syndicale. En 1974, après avoir lutté pour la régularisation de la situation des stagiaires travaillant dans l'institution, elle fut élue pour présider le premier Comité démocratique des délégués des chercheurs de l'INAH, ce qui déboucha sur l'obtention de meilleures conditions de travail et sur une grille d'avancement des chercheurs, encore en vigueur à l'heure actuelle. À partir de là, elle défendit l'idée d'une participation des chercheurs à la prise de décisions au sein de l'INAH. 
Nous garderons tous en mémoire une image intense d'Ana María Crespo Oviedo, celle d'une femme chercheur infatigable et combative. Pour beaucoup d'entre nous, elle fut une amie, généreuse et solidaire, dont la présence nous manque déjà. Elle laisse deux fils ainsi qu'une famille nombreuse et très unie ${ }^{1}$.

1. Nous tenons à remercier Carlos Viramontes (Centre INAH Queretaro), Luis Felipe Crespo Oviedo (Museo de las Culturas, Mexico) et Aldir Gonzalez Morelos (DEA, INAH) pour toutes les informations qu'ils nous ont fournies.

María Rosa Avilez Moreno, INAH, Mexico, Véronique Darras, CNRS/CEMCA, Mexico

\section{Principales publications}

1971 «Un atlante mexica y algunas consideraciones sobre los relieves del cerro de la Malinche, Hidalgo » (coauteur C. Navarrete), Estudios de cultura náhuatl, 14, UNAM, Mexico.

1974 « La ocupación en el área de Tula, Hidalgo » (coauteur A. G. Mastache), in E. Matos Moctezuma, éd., Proyecto Tula (primera parte), INAH, Mexico, pp. 71-103, coll. «Científica » 15 .

1976 Villa de Reyes, S.L.P. Un múcleo agricola en la frontera norte de Mesoamérica, INAH, Mexico, coll. "Científica » 42.

« Uso del suelo y patrón de poblamiento en el área de Tula, Hidalgo », in E. Matos Moctezuma, éd., Proyecto Tula (segunda parte), INAH, Mexico, coll. «Cientifica » 33.

1979 Hablantes de lengua indigena de México (coauteur M. L. Horcaditas de Barros), INAH, Mexico, coll. "Científica » 81.

1980 Análisis de la investigación arqueológica en Guanajuato (coauteur G. Tomé), Mecanografico, Centro regional Guanajuato, INAH, Mexico.

1981 « La presencia en el área de Tula, Hidalgo, de grupos relacionados con el barrio de Oaxaca en Teotihuacan » (coauteur A. G. Mastache), in E. Rattray, J. Litvak King et C. L. Díaz, éds, Interacción cultural en el México central, UNAM, Mexico.

"La cronología del área de Tula » (coauteurs R. Cobean, A. G. Mastache et C. L. Díaz), in E. Rattray, J. Litvak King et C. L. Díaz, éds, Interacción cultural en el México central, UNAM, Mexico, pp. 187-214.

1982 "Propuesta para la organización de la investigación en el INAH » (coauteurs B. Cervantes, L. M. Flores, M. de los Ángeles Colunga, R. Vargas, C. Castañeda), Primer Congreso nacional de investigadores del INAH, INAH, Mexico.

Estudios sobre la antigua ciudad de Tula (coauteurs A. G. Mastache, R. Cobean et D. Healan), Departamento de Monumentos Prehispánicos, INAH, Mexico, coll. «Científica » 121.

"Análisis sobre la traza general de Tula, Hidalgo » (coauteur A. G. Mastache), in Estudios sobre la antigua ciudad de Tula, Departamento de Monumentos Prehispánicos, INAH, Mexico, pp. 11-36, coll. "Científica » 121. 
1985 «El Cerrito, asentamiento prehispánico en Querétaro », Antropología, 6, INAH, Mexico.

1986 « Un planteamiento sobre el proyecto constructivo del recinto ceremonial de El Cerrito », El Heraldo de Navidad, Patronato, Querétaro.

« El Blanco levantado en la secuencia de El Cerrito, Querétaro », Taller de cerámica prehispánica del Centro-Occidente de México, ponencia, Centro Regional Michoacán, Morelia.

1988 " María Luisa Horcasitas de Barros », in C. García Mora, éd., La Antropología en Mexico : panorama histórico. Los protagonistas, INAH, Mexico, vol. X, pp. 290295.

« La arqueología en Guanajuato » (coauteurs L. M. Flores et C. Castañeda), in C. García Mora, éd., La Antropología en México : panorama histórico. La antropología en el Occidente, el Bajío, la Huasteca y el oriente de México, INAH, Mexico, vol. XIII, pp. 253-278.

«Problemas de las sociedades prehispánicas del Centro-Occidente de México. Resumen " (coauteurs R. Brambila, C. Castañeda, T. Durán, L. M. Flores et J. C. Saint-Charles), in Primera reunión sobre las sociedades prehispánicas en el Centro-Occidente de México, INAH, Centro regional de Querétaro, pp. 11-22, coll. "Cuaderno de trabajo " 1.

«Interpretación de la historia del asentamiento en Guanajuato » (coauteurs C. Castañeda, J. Contreras, J. C. Saint-Charles, T. Durán, L. M. Flores), in Primera reunión sobre las sociedades prehispánicas en el Centro-Occidente de México, INAH, Centro regional de Querétaro, pp. 321-356, coll. « Cuaderno de trabajo »1. «Elementos cerámicos en asentamientos toltecas en la región de Querétaro y Guanajuato » (coauteur L. M. Flores), in Ensayos de alfareria prehispánica e histórica de Mesoamérica. Homenaje a Eduardo Noguera, UNAM-IIA, Mexico, pp. 205-220.

1989 «Poblamiento prehispánico en el centro norte de la frontera mesoamericana » (coauteurs C. Castañeda, B. Cervantes et L. M. Flores), Antropología, 28, INAH, Mexico, pp. 28-33.

La vida airada, imágenes del agrarismo en Guanajuato (coauteurs B. Cervantes et L. M. Flores), Gobierno del Estado de Guanajuato, Mexico.

1990 «Tunal grande : frontera de equilibrio para Mesoamérica » (coauteurs B. Cervantes et L. M. Flores), Antropología, 32, pp. 14-21.

1991 "Perspectivas de la arqueología de Querétaro », A. M. Crespo et R. Brambila, éds, Querétaro prehispánico, INAH, Mexico, pp. 7-9, coll. « Científica » 238.

"Variantes del asentamiento en el valle de Querétaro. Siglos I a X d.C. ", in A. M. Crespo et R. Brambila, éds, Querétaro prehispánico, INAH, Mexico, pp. 99 136, coll. « Científica » 238.

«El recinto ceremonial de El Cerrito », in A. M. Crespo et R. Brambila, éds, Querétaro prehispánico, Mexico, INAH, pp. 163-224, coll. « Científica » 238.

1992 «El pueblo ñöñhö : colonización y arraigo » (coauteur B. Cervantes), in Historia y actualidad de los grupos indigenas de Querétaro, Gobierno del Estado de Querétaro, INAH, Centro regional Querétaro, Mexico, pp. 62-87.

«Los antiguos centros de población en los valles queretanos» (coauteur J. C. Saint-Charles), in Historia y actualidad de los grupos indigenas de Querétaro, 
Gobierno del Estado de Querétaro. INAH, Centro regional Querétaro, Mexico, pp. 31-45.

"Unidades político-territoriales », in B. Boehm de Lameiras et P. Weigand, éds, Origen y desarrollo en el Occidente de México, El Colegio de Michoacán, Mexico, pp. 157-176.

"Raíz colonial de la tradición otomiana en la región Guanajuato-Querétaro » (coauteur B. Cervantes), Historias, 24, INAH, Mexico.

Arqueología e historia antigua de Querétaro (coauteurs C. Viramontes et A. Herrera), Gobierno del Estado de Querétaro, INAH, Centro regional Querétaro, Mexico.

« Apaseo el alto, Guanajuato : una experiencia municipal » (coauteurs B. Cervantes et L. M. Flores), in Voz crítica segunda época de Querétaro, 4, INAH, Querétaro.

1993 « Estructuras de planta circular en el Bajío », Cuadernos de arquitectura mesoamericana, 25, pp. 79-88, UNAM, Facultad de Arquitectura, Mexico.

"El papel de la élite otomí en el avance hispano hacia el norte de Mexico» (coauteur B. Cervantes), in Voz crítica segunda época de Querétaro, 6, pp. 4-12, INAH, Querétaro.

« Formas arquitectónicas del Bajío. La visión en cuadrantes del espacio ceremonial » (coauteur J. C. Saint-Charles), Cuadernos de arquitectura mesoamericana, 25, pp. 59-64, UNAM, Facultad de Arquitectura, Mexico.

« Juegos de pelota en el Bajío» (coauteurs R. Brambila et J. C. Saint-Charles), Cuadernos de arquitectura mesoamericana, 25, pp. 89-95, UNAM, Facultad de Arquitectura, Mexico.

1995 " ¿ Retorno a los orígenes? El retablo del museo regional de Querétaro », in J. M. López, éd., El patrimonio sitiado : punto de vista de los trabajadores, INAH, Mexico, pp. 367-379.

1996 "Factores de autonomía y enlace de unidades político-territoriales en el valle de Querétaro ", in A. G. Mastache, J. Parsons, R. Santley et C. Serra Puche, éds, Arqueología mesoamericana. Homenaje a William T. Sanders, vol. I, Arqueología mexicana, INAH, Mexico, pp. 387-397.

"Presentación », in A. M. Crespo et C. Viramontes, éds, Tiempo y territorio en arqueología. El centro-norte de México, INAH, Mexico, pp. 9-14, coll. "Científica $" 323$.

" La tradición cerámica del blanco levantado », in A. M. Crespo et C. Viramontes, éds, Tiempo y territorio en arqueología. El centro-norte de México, INAH, Mexico, pp. 77-92, coll. « Cientifica » 323.

"Ritos funerarios y ofrendas de élite. Las vasijas Xajay ", in A. M. Crespo et C. Viramontes, éds, Tiempo y territorio en arqueología. El centro-norte de México, INAH, Mexico, pp. 115-142, coll. "Científica » 323.

"Santa Maria del Refugio : una ocupación de fase Tlamimilolpa en el Bajío » (coauteurs C. Castañeda et L. M. Flores), in A. M. Crespo et C. Viramontes, éds, Tiempo y territorio en arqueología. El centro-norte de México, INAH, Mexico, pp. 161-178, coll. « Científica » 323.

Arqueología, realidades, imaginaciones. Un recuento de la arqueología por quienes la practican (coauteurs C. Viramontes et I. Rodríguez), Delegación D-II-IA-1, Sección X del SNTE, Mexico, coll. « Debate académico » 1 . 
"La militancia de la arqueología lúdica » (coauteurs R. Brambila et F. LópezAguilar), in A. M. Crespo, C. Viramontes et I. Rodríguez, éds, Arqueología, realidades, imaginaciones : un recuento de la arqueologia por quienes la practican, Delegación D-II-IA-1, Sección X del SNTE, Mexico, pp. 297-300, coll. « Debate académico $\gg 1$.

1997 «Lápida de Soyaniquilpan », Expresión antropológica, 4-5, pp. 60-65, Instituto mexiquense de Cultura.

1998 « La expansión de la frontera norte (y la cronología oficial para Teotihuacan) », in R. Brambila et R. Cabrera, éds, Los ritmos de cambio en Teotihuacan : reflexiones y discusiones de su cronología, INAH, Mexico, pp. 323-334, coll. « Científica » 366. « Oratorios familiares, la huella de la presencia otomí en Querétaro y Guanajuato » (coauteur B. Cervantes), in E. López Calzada, éd., Primer congreso nacional de arqueología histórica, CONACULTA/INAH, Mexico, pp. 342-363.

1999 "Elementos chichimecas en las sociedades agrícolas del centro-norte de México » (coauteur C. Viramontes), in E. Williams et P. Weigand, éds, Arqueología y etnohistoria. La región del Lerma, El Colegio de Michoacán/Centro de investigaciones en matemáticas, Zamora, Michoacán, pp. 109-132.

2002 «Don Nicolás de San Luis Montañez, cacique conquistador y pacificador en la Gran Chichimeca ", in R. Brambila, éd., Episodios novohispanos de la historia otomí, Biblioteca de los pueblos indígenas, Instituto mexiquense de Cultura/ Universidad Autónoma del Estado de México, Toluca, pp. 93-138.

«El Centro norte de Mesoamérica : su organización territorial en el Clásico » (coauteur R. Brambila), in M. E. Ruiz Gallut, éd., Ideología y politica a través de materiales, imágenes y símbolos. Memoria de la primera mesa redonda de Teotihuacan, CONACULTA/INAH, Mexico.

" Documentos sobre la memoria étnica otomí en Guanajuato y Querétaro » (coauteur B. Cervantes), in F. Nava, éd., Otopames. Memoria del primer coloquio, InstiSous presse tuto de Investigaciones Antropológicas, UNAM, Mexico, pp. 79-91.

« Patrones arquitectónicos : diseño y cambios en los asentamientos del centro-norte y Occidente de México » (coauteur J. Ramos de la Vega), in E. Williams, P. Weigand et D. Grove, éds, Trabajos recientes y muevas direcciones en el Occidente de México, Guadalajara. 